\title{
Metacognitive illusion or self-regulated learning? Assessing engineering students' learning strategies against the backdrop of recent advances in cognitive science
}

\author{
Maria Cervin-Ellqvist ${ }^{1}$ (D) - Daniel Larsson ${ }^{1} \cdot$ Tom Adawi $^{1}$ (D) Christian Stöhr $^{1}$ (D) \\ Raffaella Negretti ${ }^{2}$ (D)
}

Accepted: 14 September 2020 / Published online: 23 October 2020

(C) The Author(s) 2020

\begin{abstract}
Knowing how students approach learning in higher education contexts is key to promote learning strategies that are effective in the long run. Previous research has concluded that students often use ineffective learning strategies but believe them to be effective-a phenomenon known as metacognitive illusion. In a bid to broaden the perspective on students' use of learning strategies, this study draws on the notion of self-regulated learning as a theoretical lens. A questionnaire, comprising both open-ended and closed-ended questions, was developed to gather data from 416 engineering students. The questionnaire was geared towards (1) mapping what learning strategies students use in a real-world setting, in real courses, (2) probing their metacognitive awareness of the effectiveness of various learning strategies and (3) investigating why students choose certain learning strategies. We also compared which learning strategies the engineering students chose across programs and types of courses. The findings reveal a complex picture of why students sometimes use seemingly ineffective learning strategies, and we conclude that this is not always due to metacognitive illusion. It is instead often linked to attempts to regulate behaviour, motivation and/or learning context, sometimes in response to the context. This study adds to the current HE research investigating students' abilities to reflect on, assess and take control of their learning in an effective way, confirming that students need explicit guidance.
\end{abstract}

Keywords Learning strategies $\cdot$ Self-regulated learning $\cdot$ Metacognitive illusion · Metacognition $\cdot$ Engineering education $\cdot$ Learning context

Maria Cervin-Ellqvist

maria.cervinellqvist@gmail.com

1 Department of Communication and Learning in Science, Division for Engineering Education Research, Chalmers University of Technology, Gothenburg, Sweden

2 Department of Communication and Learning in Science, Division for Language and Communication, Chalmers University of Technology, Gothenburg, Sweden 


\section{Introduction}

In higher education (HE), what happens outside the classroom-how students learn and whether they use effective learning strategies-is crucial for students' academic success. As Bjork et al. (2013, p. 418) point out, much learning in HE occurs in unsupervised fashion, and 'knowing how to manage one's own learning activities has become [...] an important survival tool'. A recent meta-analysis of research in HE has shown that, despite an overall fragmentation, topics related to teaching and learning have steadily gained ground (Daenekindt \& Huisman 2020): self-regulated learning (SRL) and metacognition have gained relevance because of their role in students' ability to self-assess their learning and make accurate evaluative judgments about the quality of their work (e.g. Boud \& Soler 2016; Tai, Ajjawi et al. 2018). The need for SRL is apparent for HE students both in relation to their future work life and the increased autonomy in HE compared with the previous phase of schooling (McDowell 2019). For instance, the transition to HE requires students to engage in 'a more self-responsible organisation of their studying in regard of content, time and study mode' (Coertjens et al. 2017, p. 359) and maintain their motivation, starting already in the first year (Coertjens et al. 2017). Furthermore, studies have emphasised differential achievement gains for students depending on type of program and institution (Dalmon et al. 2019), posing that across HE context, students' ability to take control of their learning is crucial. The importance of developing effective SRL strategies is particularly evident for engineering students, who face a fast-changing work life with increasingly complex challenges (Hadgraft \& Kolmos 2020; Wallin \& Adawi 2018; Zheng et al. 2020). Unfortunately, such learning strategies are seldom explicitly taught in HE (Bjork et al. 2013).

Research in cognitive science has underscored that students often fail to use effective learning strategies and tend to make incorrect assumptions about what effective learning is, known as metacognitive illusion (Bjork et al. 2013). Such illusions impede the development of effective strategies (Serra \& Metcalfe 2009; Tai et al. 2018). For example, students may judge that they know something just by reading it multiple times and thus decide not to study further, without testing their actual knowledge of the material. As Tai et al. (2018, p. 468) point out, 'developing students' evaluative judgement should be a goal of higher education, to enable students to improve their work and to meet their future learning needs'. However, the ideal representation of a sophisticated learner emerging from cognitive science emphasises primarily cognitive dimensions of learning: an effective learner should understand how the human mind works and engage in learning strategies that are effective for storing, retrieving and monitoring information (Bjork et al. 2013). Yet in authentic settings, the conditions affecting learning are complex, and students might choose particular strategies for various reasons. SRL, used as a theoretical lens for the present study, also emphasises the motivational and behavioural dimensions (Pintrich 2000). Finally, students inevitably have to consider the setting itself - the context-as SRL is both constantly shaped by and shaping the learning situation with every choice the student makes (Winne 2010). It is therefore crucial to study learning in naturalistic settings. Dunlosky and Rawson (2019) echo this point, arguing that cognitive scientists need to step out of the lab and use authentic educational settings as sites for data collection in order to bolster the educational relevance of their findings.

Consistent with this, we argue that the notion of metacognitive illusion has somewhat limited explanatory power as it is based on a cognitive effectiveness perspective, rather than an SRL perspective. Why students use certain strategies in relation to their learning context 
is less clear (Vermetten et al. 1999; Vermunt 2005). In particular, engineering students' use of learning strategies across different learning contexts and type of courses, and how/why they use these strategies for SRL, has yet to be investigated. Therefore, this study examines engineering students' learning strategies in two HE engineering programs. It partially replicates an experimental study by Karpicke et al. (2009), but taking learning context into account. Similarly to previous studies, we examine the most frequent strategies that students use (cf. Dunlosky et al. 2013). This research, however, departs from the hypothesis that metacognitive illusion explains students' choices of ineffective strategies. We broaden the picture and test this hypothesis in an authentic HE setting, taking into account how not only cognition but also motivation, behaviour and context may explain student's selfreported choice of strategies. In this regard, a recent study with engineering students has shown that competent self-regulated learners had the greatest ability to accurately assess their knowledge and adopt relevant learning strategies, with greater achievement gain when compared with cognitive-oriented self-regulation (Zheng et al. 2020). To take learning context into account, we consider the different programs and types of courses students are enrolled in. We include two types of courses, problem-based calculation courses and conceptual courses, that are typical for engineering programs but distinctly different from each other. Finally, we examine why students use these strategies, using Pintrich's (2000) model of SRL as a theoretical framework. Using a mixed methods research design, with data gathered through a questionnaire, this study is guided by the following research questions:

RQ1 What learning strategies do engineering students report for studying outside the classroom?

RQ2 How do the learning strategies that students apply outside the classroom differ between engineering programs and types of courses?

RQ3 How aware are students of the effectiveness of their learning strategies?

RQ4 Why do students use their specific learning strategies?

By addressing these questions, we advance the understanding of what strategies engineering students use for learning in authentic contexts, and why. Arguably, this is key to promote learning strategies that are effective in the long run. The questionnaire we developed can be used by teachers and program developers to tap into students' strategies in different learning contexts and thereby be a useful tool for these educators in developing suitable educational approaches that can scaffold students' learning effectively. As such, the questionnaire represents a valuable contribution on its own right. Our findings also point out the need for theory and research to integrate not only cognition but also motivation, behaviour and context when examining and explaining students' learning strategies in authentic HE settings.

\section{Theoretical and empirical framework}

\section{Self-regulated learning and learning strategies}

Self-regulated learning (SRL) refers to 'an active constructive process whereby students set goals for their learning and attempt to monitor, regulate, and control their cognition, motivation/affect, and behaviour guided and constrained by their goals and the contextual features' (Pintrich 2000, p. 453), i.e. set relevant learning goals and effectively make sure 
that these are met. Research has consistently shown that students who are able to engage in effective SRL perform better academically and learn better (Winne \& Hadwin 2008).

Pintrich's model of SRL categorises strategies into four areas:

- Cognition: strategies to remember and comprehend as well as metacognitive strategies to plan, monitor and evaluate comprehension, for example memorising, study old exams to understand the task, and test oneself (i.e. to evaluate comprehension)

- Motivation/affect: strategies to regulate motivation and/or affect, such as interest or liking of the task; typically more motivating than other strategies

- Behaviour: strategies used to regulate behaviour, for example seeking help or regulating effort

- Context: strategies to adapt to the context, for example choosing where to study and knowledge about the learning context and task

Each area comprises four phases: (1) forethought, planning and activation, (2) monitoring, (3) control and (4) reaction and reflection. Note that the same strategy can be used for different purposes and in different areas and phases of SRL. It can, for example, serve the double purpose of being cognitive (aimed at increasing knowledge) and part of the control phase or metacognitive (aimed at monitoring knowledge) and part of the monitoring phase.

The cognitive effectiveness of different learning strategies is well studied. Dunlosky et al. (2013) provided a comprehensive overview of previous research by evaluating the relative utility and generalisability across learning conditions, student characteristics, materials and criterion task of ten learning strategies (see also Dunlosky \& Rawson 2015), rating them as having generally high, moderate or low effectiveness (see Table 1).

Previous research on learning strategies has also investigated what strategies students use. For example, reading (Carrier 2003; Gurung 2005), rereading (Karpicke et al. 2009) and highlighting have been shown to be popular among students (cf. Dunlosky et al. 2013), while the extent to which students test or evaluate their knowledge has varied across studies (Gurung 2005; Hartwig \& Dunlosky 2012; Kornell \& Bjork 2007).

It is important to note that strategies vary in effectiveness depending on materials, subject and the learners themselves, and not only cognitive factors. For example, Dunlosky et al. (2013) suggest that summarising might deserve a higher rating for undergraduates who are skilled at it and may be used for testing. However, previous research has not always clarified what students actually do when they use a strategy. For example, reading has mostly been seen as one strategy without further differentiation (e.g. Gurung 2005; Hartwig \& Dunlosky 2012). Some research suggests that flashcards and quizzes are used to practise testing to a high extent (Hartwig \& Dunlosky 2012; Kornell \& Bjork 2007), while another study found that they are used to help memorise or because they are easy to use (Wissman et al. 2012). Clearly, there is some ambiguity about what students actually do when they use a certain strategy and why they use it, i.e. whether they use it because they (accurately or not) find it effective.

The variation in the use of strategies may also stem from differences in learning context. Some research on strategies has clearly accounted for the influence of context on choices (Afshar et al. 2014; Carrier 2003; Gurung 2005), while some have not (Karpicke et al. 2009; Van Etten et al. 1997). However, the type of course (Vermetten et al. 1999) and academic discipline (Vermunt 2005) have been shown to affect students' choices. Previous research has also shown that students adapt to exam requirements, for example by using basic strategies when those are sufficient (Abd-El-Fattah 2011; Gurung et al. 2010). Gurung et al. (2010) found that to study practice exams was positively correlated with 





exam score, even though this strategy might not always be effective for remembering the information to-be-learned (Bjork et al. 2013). Therefore, as students' use of strategies has been shown to vary in response to their context of learning, it is important to account for this variety to shed light on what happens outside the classroom: how students choose to study, and why.

In the context of our study, engineering students in STEM $^{1}$ courses, what happens outside the classroom seems relatively unstudied. Some studies have examined SRL strategies during problem solving (e.g. Wedelin et al. 2015), and over time (e.g. Lawanto \& Santoso 2012), and others have shown that metacognitive strategies affect engineering students' performance in STEM courses (Grohs et al. 2018; Ko \& Hayes 1994; Litzinger et al. 2010; Meyer et al. 2015). However, engineering students' use of learning strategies across different contexts and type of courses, and how/why they use these strategies for all areas of SRL, not only cognition, has yet to be investigated.

\section{Metacognitive illusions}

For SRL to be effective, learners need to develop accurate metacognition about whether their studying is actually getting them nearer to their learning goals-i.e. if their learning strategies are effective for them. Metacognition can be described as thinking about one's own thinking (Flavell 1979). Metacognitive illusion refers to systematic errors in metacognitive monitoring, stemming from inaccurate judgements about the effectiveness of a strategy. Students who form metacognitive illusions (Serra \& Metcalfe 2009) might not selfregulate their learning, or do it ineffectively (Zimmerman 2008). Students' metacognitive awareness has to include all areas of SRL, not only cognition (Pintrich 2000). For instance, what is effective SRL varies depending on context, since students shape their learning situation by their choices of SRL strategies (Winne 2010). Thus, it is crucial for students not only to use effective strategies but also to have metacognitive awareness of whether their strategies are effective or not to be able to engage in effective SRL.

A metareview of previous research (Bjork et al. 2013) concluded that students often fail to use effective learning strategies and tend to have incorrect assumptions about their effectiveness, thus exhibiting metacognitive illusion. These metacognitive illusions, or metacognitive awareness, about their strategy choices impact how students use strategies, and when. For example, high achieving students may use a strategy more adaptive than low achieving students (Hartwig \& Dunlosky 2012). However, studies have not always captured these nuances. For example, testing for feedback is more effective than testing (Dunlosky et al. 2013), but students' awareness of the effectiveness of testing, i.e. the testing effect (Karpicke et al. 2009), remains ambiguous if students do not explain their choices. Van Etten et al. (1997) found students metacognitively aware of the benefits of certain strategies, for example, studying in a group to avoid over- or understudying. On the contrary, Winne and Jamieson-Noel (2002) found that students did not use some powerful strategies and assigned less utility to some strategies than the researchers did. Why they did so was unclear. Additionally, students might also overestimate time or effort spent on a strategy and subsequently underestimate its overall benefit (Winne \& Jamieson-Noel 2002). In such cases, students may be metacognitively aware but still self-regulate ineffectively due to misconceptions about their behaviour. It is also possible that students do not

${ }_{1}^{1}$ Science, technology, engineering and mathematics. 
Table 2 Participant distribution over courses/programs and response rate

\begin{tabular}{lllll}
\hline & Type of course & Program & $\begin{array}{l}\text { Response rate, pro- } \\
\text { gram of interest }\end{array}$ & $\begin{array}{l}\text { Response rate, } \\
\text { students from other } \\
\text { programs }\end{array}$ \\
\hline Course 1 & Calculation & Bioengineering & $65 / 88(73.9 \%)$ & n.a \\
Course 2 & Conceptual & Bioengineering & $33 / 67(49.3 \%)$ & n.a \\
Course 3 & Calculation & Civil engineering & $51 / 129(39.5 \%)$ & $75 / 146(51.4 \%)$ \\
Course 4 & Conceptual & Civil engineering & $104 / 109(95.4 \%)$ & $88 / 101(87.1 \%)$ \\
Total & & & $253 / 393(64.4 \%)$ & $163 / 247(66.0 \%)$ \\
\hline
\end{tabular}

always use their knowledge of the benefits of certain strategies (Van Etten et al. 1997) or value other factors when choosing strategies in their specific learning context. Therefore, further research is needed on how and why students actually use strategies and if they suffer from metacognitive illusions and/or use strategies that are less effective from a cognitive perspective to regulate their learning in terms of motivation, behaviour and/or context.

\section{Method}

\section{Setting and participants}

The study was conducted in 2019 with engineering students at a leading, private, technological university in Scandinavia, with over ten thousand students; where teachers are also researchers. No tuition fees exist for citizens within the EU/EEA or Switzerland. Admission to bachelor's level requires completion of certain STEM courses in upper secondary school and selection is based on average grades.

Four courses were included in our study, belonging to one of two programs-bioengineering and civil engineering. The programs were selected as they differ substantially in content but show similar student group characteristics (e.g. average grades required for admission and a relatively equal gender distribution), increasing comparability of the groups. The courses can be distinguished by type: calculation courses (focusing on mathematical understanding) and conceptual courses (emphasizing conceptual rather than mathematical understanding). To ensure variation in learning context, the courses were selected so that they represent one of the types, but not both. All courses were traditional on-campus courses, with lectures and written exams. The calculation courses were mainly taken by first-year students, whereas the conceptual courses were mostly taken by secondyear students. Some students from other programs also enrolled in the courses and were included in the study. In total, our sample encompassed 640 students (see Table 2). Fortynine percent of the 416 students who completed the survey were women, $50 \%$ were men and $1 \%$ identified themselves as neither man nor woman.

\section{Study design and data collection}

We partially replicated a well-known experimental study by Karpicke et al. (2009), a study based on theories of metacognitive illusions that students might suffer from when choosing learning strategies, but we stepped out of the lab and into an authentic engineering 
education context. Our study adopted a concurrent mixed methods design (Driscoll et al. 2007), with qualitative and quantitative data collected through a questionnaire (see Appendix).

Our questionnaire consisted of two open-ended questions and one closed-ended question. Similar to Karpicke et al. (2009), our first open-ended question asked students to list their strategies and order them by frequency of use. Our second open-ended question asked students to motivate their three most used strategies, to address the ambiguity about why and how students use their strategies. Students could list several reasons.

As in Karpicke et al. (2009), the third question aimed at measuring the perceived effectiveness of different learning strategies. After the pilot (see below), we replaced the original question with a list of seven of the ten strategies evaluated by Dunlosky et al. (2013). Three strategies were excluded (see Table 1) because they refer to scheduling, which is outside the scope of our study, or because of their relevance primarily for younger students. The students were asked to select the strategies they used and rate their effectiveness on a Likert scale ranging from one to six, and could comment on their answers.

The survey was conducted in Swedish to avoid misunderstandings and translated to English by the authors. A pilot with five senior students from the same programs in a focus group led to small modifications in wording and the revision of the third question, which generated ambiguous answers as it asked students to choose which one of two strategies they would use in a given situation and explain why. The students in the focus group thought that this was not a realistic situation and had difficulties interpreting the question. The survey was conducted with pen and paper at course occasions to maximise response rate. Of the 640 students, 416 (65\%) completed the survey (Table 2). Informed consent was obtained.

\section{Data analysis}

The answers to the two open-ended questions were manually coded by the two first authors using inductive thematic analysis (Braun \& Clarke 2006). The intercoder reliability (Lombard et al. 2017) exceeded $90 \%$. The names of categories were mainly derived from the student's own answers.

We calculated the proportion of students listing each strategy, as well as the proportion listing it as their top strategy (RQ1). Occasionally, students reported more than one strategy as their top strategy, and we included both in the analysis.

To test whether differences were significant across types of courses and programs (RQ2), we used chi-square (Devore 2012) and Cramér's $V$ as a measure of the strength of the association (McHugh 2018). We also listed the most frequent strategies in each course to see if and how these differed between programs and/or types of courses. The students that were not enrolled in the bioengineering or civil engineering program were excluded from the comparative analysis (RQ2).

Further, we calculated the perceived effectives of each learning strategy (RQ3) as the mean of students' ratings on the six-point Likert scale. We also identified the proportion of students using a strategy they rated as having a low effectiveness, i.e. one or two on the Likert scale.

After analysing why students use their strategies through inductive coding, we created a graph to provide an overview for each learning strategy of all reasons stated by at least $10 \%$ of all students using this strategy (RQ4). For each of the ten most used strategies, we further selected representative quotes to illustrate more in-depth why they chose it. Finally, 
Table 3 The ten most used strategies overall and the students' number one strategy

\begin{tabular}{lllll}
\hline Strategy & $\begin{array}{l}\text { Percent who } \\
\text { list strategy }\end{array}$ & $N$ & $\begin{array}{l}\text { Percent who rank } \\
\text { as \#1 strategy }\end{array}$ & $n$ \\
\hline 1. Study old exams & 83.2 & 346 & 38.5 & 160 \\
2. Read course material/notes & 63.0 & 262 & 22.1 & 92 \\
3. Do practice problems & 46.6 & 194 & 20.0 & 83 \\
4. Summarise & 31.3 & 130 & 11.8 & 49 \\
5. Search for information through alternative resources & 19.5 & 81 & 1.4 & 6 \\
6. Discuss with others & 17.5 & 73 & 3.1 & 13 \\
7. Flashcards/quizzes & 11.8 & 49 & 1.4 & 6 \\
8. Study things one finds hard/do not know & 11.1 & 46 & 1.2 & 5 \\
9. Restudy/repetition & 9.4 & 39 & 1.0 & 4 \\
10. Study in a group & 8.2 & 34 & 2.2 & 9 \\
\hline
\end{tabular}

we mapped the students' reasons for strategies against the different areas of Pintrich's SRL model.

\section{Results}

\section{Overall use of learning strategies (RQ1)}

Students reported using a wide range of learning strategies - 28 in total, with an average of 3.18 strategies $(S D=0.96)$. The overall distribution of the ten most used strategies for the entire sample is presented in Table 3. Of note is that students tend to gravitate towards using the top four strategies, in particular as their strategy of first choice.

\section{Comparing the use of learning strategies between programs/courses (RQ2)}

Findings pertaining to the second research question are reported in Table 4. There is essentially no difference in reported learning strategies across programs, but a notable difference across type of course (calculation vs conceptual). The top four strategies were the same in the calculation courses; in the conceptual courses, the top three strategies were the same (but carried different ranking positions).

This finding was corroborated by a chi-square test (see Table 5), which revealed a statistically significant difference between types of courses. No statistically significant differences emerged when comparing courses of the same type. Importantly, these findings suggest that students are able to adapt their learning strategies to the context and course/task demands.

\section{Students' awareness of the effectiveness of their strategies (RQ3)}

Students' perceptions of the effectiveness of their learning strategies are reported in Table 6. Overall, students seem aware of which strategies are the most effective. For example, in agreement with Dunlosky et al. (2013), practice testing was rated highest by our 


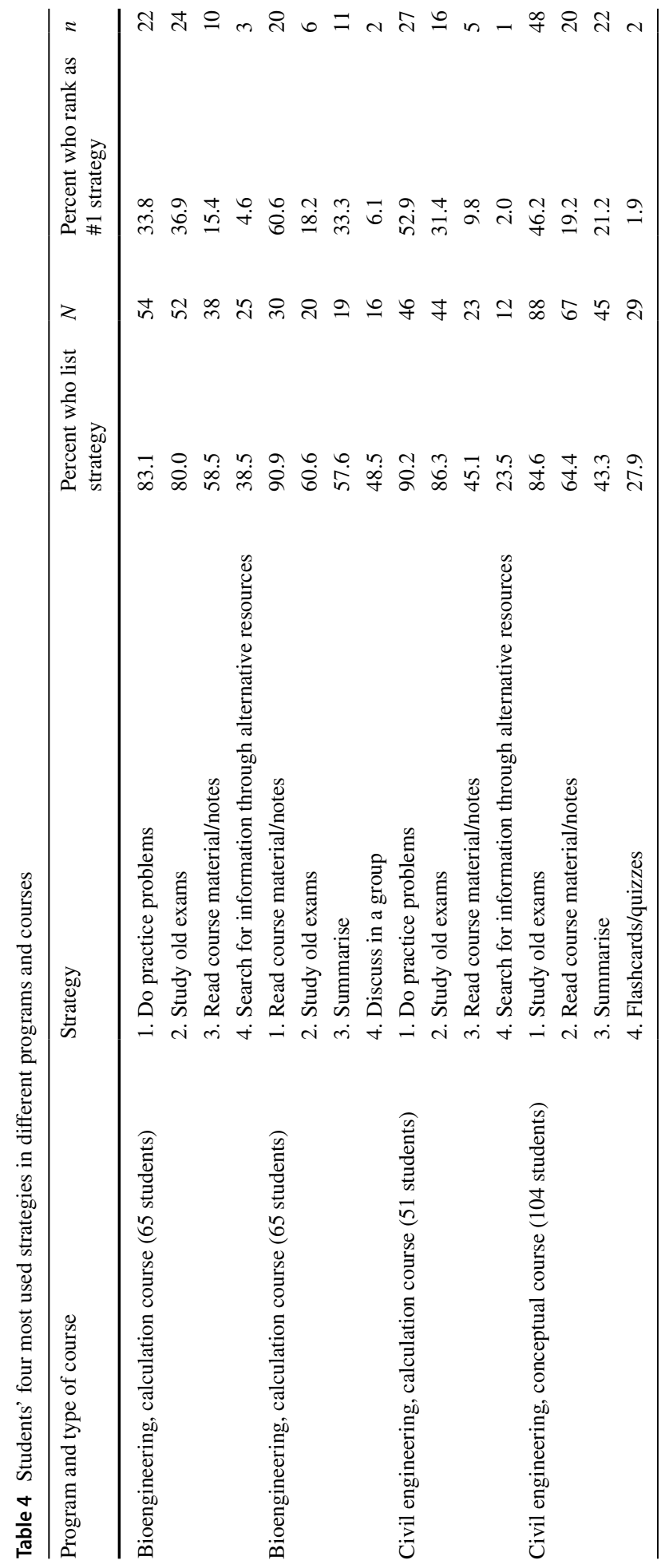


Table 5 Chi-square tests for learning strategies across types of courses and programs

\begin{tabular}{llllll}
\hline $\begin{array}{l}\text { Test for significance between learning } \\
\text { strategies and... }\end{array}$ & $N$ & $d f$ & Value & $\begin{array}{l}\text { Asymptotic signifi- } \\
\text { cance (2-sided) }\end{array}$ & $\begin{array}{l}\text { Cramer's } V \text { test } \\
\text { for association }\end{array}$ \\
\hline ..type of courses & 900 & 27 & 171.117 & 0.000 & 0.436 \\
...calculation courses in each program & 439 & 22 & 28.766 & 0.152 & - \\
...conceptual courses in each program & 473 & 27 & 39.903 & 0.052 & - \\
\hline
\end{tabular}

Table 6 Students' rating of the effectiveness of their learning strategies in comparison with Dunlosky et al.'s (2013) rating

\begin{tabular}{lllll}
\hline Strategy & $M$ & $S D$ & $N$ & Dunlosky et al. (2013) \\
\hline Practice testing & 5.12 & 0.950 & 303 & High \\
Self-explanation & 4.96 & 0.978 & 217 & Moderate \\
Elaborative interrogation & 4.90 & 1.013 & 196 & Moderate \\
Summarisation & 4.84 & 1.113 & 235 & Low \\
Keyword mnemonic & 4.60 & 1.114 & 171 & Low \\
Rereading & 4.26 & 1.181 & 318 & Low \\
Highlighting/underlining & 3.66 & 1.269 & 118 & Low \\
\hline
\end{tabular}

participants. Interestingly, students in average rated all strategies at least as moderately effective, even those that previous research rates as not very effective (Dunlosky et al. 2013).

In addition, 66 students (15.9\%) reported using low-effectiveness strategies, ${ }^{2}$ which they rated at two or less on the Likert scale. Most of these ratings belonged to rereading and highlighting/underlining. This suggests that students choose some strategies not only based on their beliefs about their effectiveness, as became clear in their explanations to why they used them (see next section).

\section{Why students use their learning strategies (RQ4)}

Students reported many different reasons; in total, 22 reasons were identified. Reasons reported by at least $10 \%$ of the students for the ten most used strategies are presented in Fig. 1. The graph provides a complex picture: some strategies had a wide range of reasons, while others did not.

In the following section, we compare the students' reasons for their strategies to Pintrich's model of SRL. We map students' strategies against this model by separating strategies used for mostly cognitive and metacognitive purposes and those tied to the self-regulation of motivation, behaviour and context.

\footnotetext{
2 This data is not in Table 6
} 


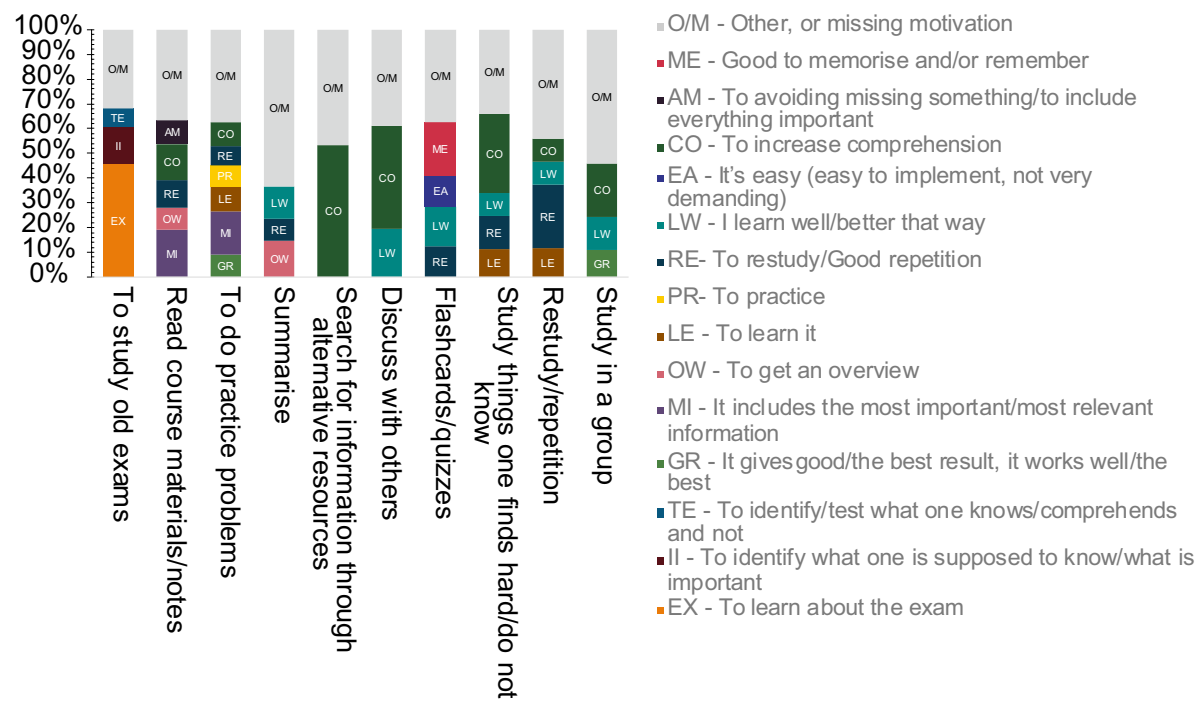

Fig. 1 The reasons listed by at least $10 \%$ of the students for the ten most frequently used learning strategies. Note that each bar in this graph corresponds to $100 \%$ of the reasons for a strategy. As some students listed several reasons and were only asked to motivate their three most often used strategies, the number of reasons is not the same as the number of students. The strategies are ordered from left to right by their frequency of use (see Table 3)

\section{Strategies used for mostly cognitive and metacognitive purposes}

The four most used strategies, as well as study things one finds hard/do not know, restudy/ repetition and flashcards/quizzes, fall into the 'cognition' area in Pintrich's model of SRL, comprising both cognitive and metacognitive strategies.

The most frequent strategy, to study old exams, was used primarily as a metacognitive forethought/planning strategy to identify the task and set goals:

In other courses I have learnt that the exams are often similar to each other and therefore this strategy is the most profitable.

To see how it is structured, what type of questions will come. To see if some questions are recurring and if so, maybe put down more time on that topic.

About $10 \%$ of the students used it to test themselves, again metacognitively, to monitor and/or evaluate their comprehension:

A good way to test what one knows...

A good way to test myself compared to the level of difficulty on previous exams.

The strategy to read course material/notes was used for a wider variety of reasons making it unclear how the students used it and why (see Fig. 1). The top three reasons for reading course material/notes could involve passive reading or active reading strategies to identify key concepts. On the other hand, both the fourth and the fifth reasons, to avoid missing something/to include everything important and to get an overview, suggest a metacognitive approach to learning, either to monitor and test one's learning or as a forethought strategy:

... so one does not miss anything. 
Read through in order to understand the entirety of the course

To get a quick overview of the course content

Students seem to use the third most frequent strategy, to do practice problems, in a metacognitive way to monitor learning and check whether they know the most important concepts to solve these problems, but also as a cognitive strategy to exercise their skills:

Because [the teacher] himself has said that these [problems] represent the course material well (I only do the ones I feel like I need to do)

The more I practise calculations the more experience I get in using the techniques, and thus also better comprehension.

To learn to solve tasks and to encounter things I might have missed.

I want to have time to do many problems to become more secure.

The strategy summarise was used mostly to get an overview, i.e. as a metacognitive forethought strategy:

Summaries give a good overview of the whole course.

Good way to get a broad overview of the course.

It was also used as a cognitive strategy to restudy. In addition to the reasons shown in Fig. 1, 5.4\% (seven students) summarised to identify/test what one knows/comprehends and not, i.e. as a metacognitive strategy used to evaluate their knowledge:

I get to say it in my own words, it is a bit like explaining it to someone - you get confirmation on what you know.

Shows if I have understood what I think that I have understood by having to ... explain.

The eighth most frequently used strategy, to study things one finds hard/do not know, seems to be used almost exclusively as a cognitive strategy to increase knowledge and comprehension. The fact that students specifically studied the hard parts means they also had to metacognitively monitor what was hard/they did not understand.

Sometimes something is unclear after a lecture, and therefore it is good to have a look in the book to see if one can understand it better.

I do this to increase my comprehension ...

The ninth most frequently used strategy restudy/repetition was used for relatively similar reasons as study things one finds hard/do not know. However, as opposed to study things one finds hard/do not know, the students did not indicate any selection of what to restudy, which suggests a cognitive rather than metacognitive approach:

As the courses often move forward fast, it is good to look back on what you have done to refresh your memory.

Restudy — Go through summaries over and over again until one has learnt them.

Repetition is the key to learning.

Flashcards/quizzes was one of the strategies used for several purposes, but it was mostly used as a cognitive strategy to memorise information:

Good way to memorise words' definitions.

Good to memorise. Easy to study on your own. 
Even though flashcards/quizzes could be used to evaluate knowledge, the students did not report doing so to any high extent.

Finally, some strategies were used to a high extent as cognitive/metacognitive learning strategies to increase comprehension: search for information through alternative resources, discuss with others and study in a group. However, since these strategies seem to overlap with other areas of Pintrich's model of SRL, we address them in more detail below.

\section{Strategies tied to the self-regulation of motivation, behaviour and context}

Some of the reasons indicated by the students for their strategies suggested SRL not only of cognition but also of behaviour, motivation and/or context (Pintrich 2000). In addition, these reasons clarify whether or not the students have metacognitive illusions about their strategies.

Flashcards/quizzes was not only used as a cognitive strategy, but also because it demands little effort, suggesting the regulation of effort and behaviour, and because it is fun $(8.2 \%)$, suggesting the regulation of motivation/affect:

Fun way of studying theory.

Good with flashcards because it takes little time to restudy a lot, app on the phone etc.

Furthermore, the strategy was used far more in the conceptual course for civil engineering than in other courses, as shown in Table 4, since in this course, flashcards were available for the students online:

It was fun and there were already made flashcards that felt comprehensive.

Found flashcards on the internet.

Some strategies fell into several areas of Pintrich's model of SRL, which was not surprising as the areas overlap. Three strategies were clear examples of this overlap, as students used them to regulate both cognition and other areas, for example, by seeking help (Pintrich 2000).

The strategy search for information through alternative resources was used mostly to increase comprehension. This indicates that the students actively sought help, i.e. regulated their behaviour, to comprehend better and get additional perspectives on the course content, i.e. used it as a cognitive and metacognitive strategy:

By searching for information in different ways you can discover new perspectives/ ways to think.

It helps to hear several people explain the same thing.

If I do not understand how to solve a problem, it helps if I see how someone else would have done it.

[Strategy: Google things I do not understand to get another explanation] To get a new perspective or increased comprehension

Similarly, the strategy discuss with others was also used mostly to increase comprehension. It was also used because I learn well/better that way. Both reasons suggest that the students use the strategy to regulate not only their cognition and behaviour but also their context, by setting up conditions for learning that they perceive as beneficial. Some also mentioned a benefit in terms of motivation, the fourth area of Pintrich's model of SRL:

Good for deeper comprehension, plus extra motivation to actually study when you 
are with classmates.

You may have notes/understood slightly different things and may then help each other, get a deeper understanding.

To discuss with classmates is good because I feel like I learn a lot and sometimes they know things you yourself have missed.

The strategy to study in a group had many similarities to discuss with others, as students mostly used it to increase comprehension, self-regulating both 'cognition' and 'behaviour' in Pintrich's model:

Study in a group makes it possible to ask someone when one does not understand and help each other.

Some students reported studying in groups because it is easier to focus/spend time on (8.8\%), because it is fun (5.9\%) and because it feels good (5.9\%), i.e. to regulate behaviour and motivation/affect:

Together because I find it hard to study by myself.

I have a hard time putting down enough time and to focus when I study by myself; to study with 3 classmates makes it easier.

Less frustrating to absorb someone else's knowledge than to hit a wall several times

Some comments revealed an awareness that the same strategies can be both effective and ineffective:

To solve tasks together is often more fun and you can help each other comprehend, but [it] can also be distracting.

As indicated by these quotes, students used study in a group as a cognitive strategy not only to learn but also to regulate their motivation, behaviour and context. Students also regulated their context by choosing to study in a group instead of on their own.

In sum, this analysis reveals that some strategies are clearly cognitive, used to learn or monitor learning, while others are used for regulation of behaviour and/or motivation. Some strategies are used across different SRL areas and therefore occur several times in the sections above. It is clear that learning context matters to the students in a number of ways, a point to which we will return in the 'Discussion' section.

\section{Discussion}

The aim of this study was to examine students' choice of learning strategies in response to learning context and through a broad perspective of SRL, including not only cognition but also motivation, behaviour and context. Therefore, we examined the learning strategies of students in HE engineering programs by (1) mapping which strategies engineering students use across courses, (2) probing their metacognitive awareness of the effectiveness of different strategies and (3) investigating why the students choose certain strategies. The students' reasons for choosing certain strategies were further analysed using Pintrich's model of SRL.

Our findings reveal a complex picture of how students learn outside of class, and why. Students used a wide range of strategies, with study old exams as the far most frequent. While there was no difference across programs, a significant difference was found across 
types of courses. In general, students were aware of the effectiveness of their strategies, as emerged from their rating.

\section{Metacognitive illusion or self-regulated learning?}

Interestingly, students did not only use strategies for cognitive/metacognitive purposes, the main focus in previous research (e.g. Dunlosky et al. 2013; Grohs et al. 2018; Karpicke et al. 2009), but also to regulate behaviour, motivation, and their learning context. In other words, students used strategies from all areas and phases in Pintrich's model of SRL.

In addition, strategies such as to study old exams, search for information through alternative resources, discuss with others and study in a group suggest that students used strategies for both cognitive/metacognitive purposes and to regulate motivation and/or behaviour at once, i.e. as part of several areas of Pintrich's model of SRL. These strategies also suggest that learning context was important for how our participants chose to study, and why. They seem to be a reaction to certain aspects of the context, an awareness of lacking comprehension (i.e. metacognitive monitoring) and often an attempt to regulate the context, as described by Winne (2010). Some students used strategies because they were easy to use. This could be a sign of students learning ineffectively, i.e. metacognitive illusion (Bjork et al. 2013). However, our results suggest caution in interpreting these results as lacking metacognitive awareness. As one student explained:

It is easy, and one can do it everywhere, it does not take as much energy, but it does not help as much either.

Further, the students' rating of the effectiveness of different strategies suggest that many are indeed metacognitively aware of the usefulness of different strategies and the importance of considering learning context, behaviour, and motivation as well as cognition. As students on average were aware that testing is effective and reading not that effective, we also examined whether the students who used both strategies $(N=255)$ rated testing higher than rereading. In contrast to previous research (Karpicke et al. 2009), we found that a majority of our participants $(63 \%)$ considered testing more effective than rereading (correctly, cf. Dunlosky et al. 2013), while only $15 \%$ rated rereading as more effective. This speaks in favour of our participants' metacognitive awareness.

Still, some students used strategies they themselves considered not very effective. Their explanations suggest that in self-regulating their learning, they did consider not only cognitive effectiveness but also their context, behaviour and motivation. Regardless of why they use these strategies, these results further strengthen the conclusion that students were relatively metacognitively aware of both the effectiveness of their strategies and other important factors for learning outside of class.

\section{Implications for theory and practice}

Our study adds to the understanding of HE students' self-regulation of their learning and corroborates previous research emphasizing the importance of self-regulation, which rests on accurate metacognition and evaluative judgments, for students in HE (e.g. Boud \& Soler 2016; Negretti 2017; Tai et al. 2018; Zheng et al. 2020). However, a study with engineering students has shown that only self-regulation of cognition does not lead to the greatest gains in achievement (Zheng et al. 2020), with potential consequences for lifelong learning (see Hadgraft \& Kolmos 2020, on the complexity of lifelong learning in engineering). Our 
study continues this line of research and emphasises the need to use theory that encompasses all areas of SRL, not only cognition, when studying students' learning outside of class. It thereby contributes to cognitive and educational science by exemplifying how Pintrich's model of SRL can be used together with insights from previous research on learning strategies to examine and explain learning in authentic HE settings. This responds to Dunlosky and Rawson's (2019) call for translation of theories into authentic educational settings to make an impact on practice.

The importance of making an impact on practice was evident in our study: even when considering all aspects of students' strategy choices mentioned in the previous section , some students did seem to suffer from metacognitive illusion, for example students who thought repetition was highly effective. This emphasises the need for teachers to help students become better learners, and not leave it to the students to figure it out on their own, as is more common in HE (Bjork et al. 2013). One student for instance wrote:

I would like to get suggestions on learning strategies from the teachers, for every course.

This also highlights that teachers have to take learning context and other factors (e.g. all areas of Pintrich's model of SRL) into consideration to develop suitable educational approaches to scaffold students' learning effectively (Dunlosky \& Rawson 2019), a scaffolding that is often very limited as teachers tend to focus on the course content (Moos \& Ringdal 2012).

The questionnaire we developed is a contribution in itself, as it has the potential to be a tool for teachers and program developers to understand students' learning strategies in different contexts and thereby determine how best to scaffold their learning. Similarly, it can be used to help students reflect upon their strategies:

This gave me some new suggestions, but also made me realise some things I use.

Students can indeed regulate, effectively or ineffectively, without conscious thought, as the process of activating previous knowledge about strategies can happen automatically (Pintrich 2000). Completing our questionnaire can turn students' attention to this process and thereby helping them make conscious decisions about their learning.

\section{Limitations and future research}

Since we did not include an assessment of students' goals or performance, we cannot conclude whether the students' learning strategies were effective or not. Similarly, we did not collect data about the participants' age and cannot conclude whether there were differences between age groups. We did collect data about gender to provide as background information, but similar to Karpicke et al. (2009), we did not aim to compare across gender. This could be addressed in future research. Our study also has the general limitations of self-report data (Winne \& Jamieson-Noel 2002) and relies on our interpretation of the students' answers and the students' interpretation of the questions. Further, our study entails the variability limitations inevitable of research in authentic settings: the conceptual and the calculation courses were not identical to each other and the teachers were not the same, which might have affected the results as teachers may impact what strategies their students use (Bielaczyc et al. 1995). Finally, the conceptual courses were part of the second year and the calculation courses of the first year: as was 
suggested by the students in the pilot, students might change their strategies over time and with increased experience, which would have affected our comparison.

Future research could combine our questionnaire with interviews, focus groups and performance data to gain an even deeper insight into what happens outside class and why, as well as the effect on actual student learning. In particular, more research is needed on how students use their metacognitive awareness and make evaluative judgements when regulating their learning and choosing learning strategies in authentic settings. This would provide a valuable addition to the current understanding of the role of students' evaluative judgements and their level of accuracy, including metacognitive illusions, in students' choice of learning strategies (e.g. Tai et al. 2018). Future research should also aim to link students' choice of strategies, metacognitive awareness about the effectiveness of different strategies and SRL to their conceptions of learning, i.e. what learning is and how it occurs (Entwistle \& Peterson 2004), across contexts. Finally, future research could look into how higher education teachers are trained in scaffolding students' use of effective strategies and self-regulated learning, as previous research suggests they often do not include this in their teaching (e.g. McGrath et al. 2019; Moos \& Ringdal 2012).

\section{Conclusions}

This study contributes by furthering our understanding of how HE students approach their study outside of class, and why, in authentic situations. We mapped engineering students' learning strategies and found that they differed across two types of courses-conceptual and calculation-based courses. We also provided a complex picture of why students sometimes use seemingly ineffective strategies and illustrated that this is not always due to metacognitive illusion, as suggested by previous research, but may be linked instead to attempts to self-regulate behaviour, motivation, and in response to their learning context. We conclude that all four areas of SRL are crucial for HE students' success and that teachers and program developers in HE need to provide explicit guidance to help students become effective learners in the short run, in their courses, and for lifelong learning.

Author contributions All authors contributed to the study's conception and design. Material preparation, data collection and analysis were performed by Maria Cervin-Ellqvist and Daniel Larsson. The draft of the manuscript was written by Maria Cervin-Ellqvist. Raffaella Negretti, Tom Adawi and Christian Stöhr supervised the work, co-wrote and commented on the manuscript. All authors read and approved the final manuscript.

Funding Open access funding provided by Chalmers University of Technology.

\section{Compliance with ethical standards}

Conflict of interest The authors declare that they have no conflict of interest.

Ethical approval All procedures performed in studies involving human participants were in accordance with the ethical standards of the institutional and/or national research committee and with the 1964 Helsinki declaration and its later amendments or comparable ethical standards.

Informed consent Informed consent was obtained from all individual participants included in the study. 


\begin{tabular}{|c|c|c|c|c|c|c|c|c|c|}
\hline \multicolumn{10}{|c|}{$\begin{array}{l}\text { What strategies do you use when you study for the exam in [course name]? List all strategies you use and rank- } \\
\text { order them from the ones you use the most often to the ones you use the least often. }\end{array}$} \\
\hline \multicolumn{10}{|c|}{$\begin{array}{l}\text { Motivate for each one of your three most used strategies why you use them? } \\
\text { (If you listed fewer than three strategies, motivate for the ones you listed.) }\end{array}$} \\
\hline \multicolumn{10}{|c|}{$\begin{array}{l}\text { Answer the question by following the two steps below. If you have an } \\
\text { the bottom of the page. } \\
\text { 1) Read the strategies carefully and check the ones you use in the cour } \\
\text { 2) How effective do you think the strategies you checked are to learn } \\
\text { [course name]? Circle one number for each of the strategies you use. } \\
\text { I use this } \\
\text { strategy }\end{array}$} \\
\hline & $\begin{array}{l}\text { Identify/come up with keywords and } \\
\text { create mental images of those to } \\
\text { remember/learn the information } \\
\text { linked to the keywords }\end{array}$ & Low effectiveness & 1 & 2 & 3 & 4 & 5 & 6 & $\begin{array}{l}\text { High } \\
\text { effectiveness }\end{array}$ \\
\hline & Write summaries & Low effectiveness & 1 & 2 & 3 & 4 & 5 & 6 & $\begin{array}{l}\text { High } \\
\text { effectiveness }\end{array}$ \\
\hline & $\begin{array}{l}\text { Check what you know of the course } \\
\text { content by testing yourself on it }\end{array}$ & Low effectiveness & 1 & 2 & 3 & 4 & 5 & 6 & $\begin{array}{l}\text { High } \\
\text { effectiveness }\end{array}$ \\
\hline & $\begin{array}{l}\text { Read course material and/or your } \\
\text { own notes more than once }\end{array}$ & Low effectiveness & 1 & 2 & 3 & 4 & 5 & 6 & $\begin{array}{l}\text { High } \\
\text { effectiveness }\end{array}$ \\
\hline & $\begin{array}{l}\text { Highlight or underline in books or } \\
\text { notes }\end{array}$ & Low effectiveness & 1 & 2 & 3 & 4 & 5 & 6 & $\begin{array}{l}\text { High } \\
\text { effectiveness }\end{array}$ \\
\hline & $\begin{array}{l}\text { Try to explain to oneself why facts or } \\
\text { concepts are true/correct }\end{array}$ & Low effectiveness & 1 & 2 & 3 & 4 & 5 & 6 & $\begin{array}{l}\text { High } \\
\text { effectiveness }\end{array}$ \\
\hline & $\begin{array}{l}\text { Try to explain to oneself how new } \\
\text { information is related to old, or } \\
\text { explain the different steps taken } \\
\text { when solving a problem/a task }\end{array}$ & Low effectiveness & 1 & 2 & 3 & 4 & 5 & 6 & $\begin{array}{l}\text { High } \\
\text { effectiveness }\end{array}$ \\
\hline
\end{tabular}

Fig. 2 The questions included in the questionnaire, translated to English. The course name has been replaced with [course name] to maintain anonymity

Open Access This article is licensed under a Creative Commons Attribution 4.0 International License, which permits use, sharing, adaptation, distribution and reproduction in any medium or format, as long as you give appropriate credit to the original author(s) and the source, provide a link to the Creative Commons licence, and indicate if changes were made. The images or other third party material in this article are included in the article's Creative Commons licence, unless indicated otherwise in a credit line to the material. If material is not included in the article's Creative Commons licence and your intended use is not permitted by statutory regulation or exceeds the permitted use, you will need to obtain permission directly from the copyright holder. To view a copy of this licence, visit http://creativecommons.org/licenses/by/4.0/. 


\section{Appendix}

The questions included in the questionnaire, translated to English, can be seen in Fig. 2. Some background questions were also included to correctly identify which program the students were enrolled in.

\section{References}

Abd-El-Fattah, S. M. (2011). The effect of test expectations on study strategies and test performance: a metacognitive perspective. Educational Psychology, 31(4), 497-511. https://doi.org/10.1080/01443 410.2011.570250

Afshar, H. S., Moazam, I., \& Arbabi, H. R. (2014). Engineering and humanities students' strategies for vocabulary acquisition: an Iranian experience. Linguistik online, 65(3), 45-64. https://doi.org/10.13092 /lo.65.1403.

Bielaczyc, K., Pirolli, P. L., \& Brown, A. L. (1995). Training in self-explanation and self-regulation strategies: investigating the effects of knowledge acquisition activities on problem solving. Cognition and instruction, 13(2), 221-252. https://doi.org/10.1207/s1532690xci1302_3

Bjork, R. A., Dunlosky, J., \& Kornell, N. (2013). Self-regulated learning: beliefs, techniques, and illusions. Annual review of psychology, 64, 417-444. https://doi.org/10.1146/annurev-psych-113011-143823

Boud, D., \& Soler, R. (2016). Sustainable assessment revisited. Assessment \& Evaluation in Higher Education, 41(3), 400-413. https://doi.org/10.1080/02602938.2015.1018133

Braun, V., \& Clarke, V. (2006). Using thematic analysis in psychology. Qualitative Research in Psychology, 3(2), 77. https://doi.org/10.1191/1478088706qp063oa

Carrier, L. M. (2003). College students' choices of study strategies. Perceptual and Motor skills, 96(1), 54-56. https://doi.org/10.2466/pms.2003.96.1.54

Coertjens, L., Brahm, T., Trautwein, C., \& Lindblom-Ylänne, S. (2017). Students' transition into higher education from an international perspective. Higher Education, 73(3), 357-369. https://doi.org/10.1007/ s10734-016-0092-y

Daenekindt, S., \& Huisman, J. (2020). Mapping the scattered field of research on higher education. A correlated topic model of 17,000 articles, 1991-2018. Higher Education, 1-17. https://doi.org/10.1007/ s10734-020-00500-X.

Dalmon, D. L., Fonseca, I., Avena, C. P., Carnoy, M., \& Khavenson, T. (2019). Do students make greater achievement gains in some higher education institutions' programs than others? Insights from Brazil. Higher Education, 78(5), 887-910. https://doi.org/10.1007/s10734-019-00376-6

Devore, J. L. (2012). Probability and statistics for engineering and the sciences (8th ed.). California: Brooks/Cole, Cengage Learning.

Driscoll, D. L., Appiah-Yeboah, A., Salib, P., \& Rupert, D. J. (2007). Merging qualitative and quantitative data in mixed methods research: how to and why not. Ecological and Environmental Anthropology, 3, 19-28.

Dunlosky, J., Rawson, K. A., Marsh, E. J., Nathan, M. J., \& Willingham, D. T. (2013). Improving students' learning with effective learning techniques: promising directions from cognitive and educational psychology. Psychological Science in the Public Interest, 14(1), 4-58. https://doi.org/10.1177/15291 00612453266

Dunlosky, J., \& Rawson, K. A. (2015). Practice tests, spaced practice, and successive relearning: tips for classroom use and for guiding students' learning. Scholarship of Teaching and Learning in Psychology, 1(1), 72. https://doi.org/10.1037/st10000024

Dunlosky, J., \& Rawson, K. (2019).How cognitive psychology can inform evidence-based education reform. In J. Dunlosky \& K. Rawson (Eds), The Cambridge handbook of cognition and education (Cambridge handbooks in psychology), 1-13. Cambridge: Cambridge University Press., 1-13. https://doi. org/10.1017/9781108235631.

Entwistle, N. J., \& Peterson, E. R. (2004). Conceptions of learning and knowledge in higher education: relationships with study behaviour and influences of learning environments. International journal of educational research, 41(6), 407-428. https://doi.org/10.1016/j.ijer.2005.08.009

Flavell, J. H. (1979). Metacognition and cognitive monitoring: a new area of cognitive-developmental inquiry. American psychologist, 34(10), 906. https://doi.org/10.1037/0003-066X.34.10.906 
Grohs, J. R., Knight, D. B., Young, G. D., \& Soledad, M. M. (2018). Exploring academic performance paths and student learning strategies in a large foundational engineering course. International Journal of Education in Mathematics, Science and Technology, 6(3), 241-253. https://doi.org/10.18404/ijems t.428175.

Gurung, R. A. (2005). How do students really study (and does it matter). Education, 39, 323-340.

Gurung, R. A., Weidert, J., \& Jeske, A. (2010). Focusing on how students study. Journal of the Scholarship of Teaching and Learning, 28-35. Retrieved from https://scholarworks.iu.edu/journals/index.php/josot 1/article/view/1734.

Hadgraft, R. G., \& Kolmos, A. (2020). Emerging learning environments in engineering education. Australasian Journal of Engineering Education, 1-14. https://doi.org/10.1080/22054952.2020.1713522.

Hartwig, M. K., \& Dunlosky, J. (2012). Study strategies of college students: are self-testing and scheduling related to achievement? Psychonomic Bulletin \& Review, 19(1), 126-134. https://doi.org/10.3758/ s13423-011-0181-y

Karpicke, J. D., Butler, A. C., \& Roediger, H. L., III. (2009). Metacognitive strategies in student learning: do students practise retrieval when they study on their own? Memory, 17(4), 471-479. https://doi. org/10.1080/09658210802647009

Ko, E. I., \& Hayes, J. R. (1994). Teaching awareness of problem-solving skills to engineering freshmen. Journal of Engineering Education, 83(4), 331-336. https://doi.org/10.1002/j.2168-9830.1994.tb001 27.x

Kornell, N., \& Bjork, R. A. (2007). The promise and perils of self-regulated study. Psychonomic Bulletin \& Review, 14(2), 219-224. https://doi.org/10.3758/BF03194055

Lawanto, O., \& Santoso, H. B. (2012). Implementation of enhanced guided notes to promote students' metacognitive self-regulated learning strategies while learning electric circuit concepts. Paper presented at the 2012 Frontiers in Education Conference Proceedings.

Litzinger, T. A., Meter, P. V., Firetto, C. M., Passmore, L. J., Masters, C. B., Turns, S. R., \& Zappe, S. E. (2010). A cognitive study of problem solving in statics. Journal of Engineering Education, 99(4), 337-353. https://doi.org/10.1002/j.2168-9830.2010.tb01067.x

Lombard, M., Snyder-Duch, J., \& Campanella Bracken, C. (2017). Intercoder reliability. In M. Allen (Ed.), The SAGE encyclopedia of communication research methods. Thousand Oaks, California: SAGE Publications, Inc.

McDowell, L. D. (2019). The roles of motivation and metacognition in producing self-regulated learners of college physical science: a review of empirical studies. International Journal of Science Education, 41(17), 2524-2541. https://doi.org/10.1080/09500693.2019.1689584

McGrath, L., Negretti, R., \& Nicholls, K. (2019). Hidden expectations: scaffolding subject specialists' genre knowledge of the assignments they set. Higher Education, 78(5), 835-853. https://doi.org/10.1007/ s10734-019-00373-9

McHugh, M. L. (2018). Cramér's V Coefficient. In B. B. Frey (Ed.), The SAGE encyclopedia of educational research, measurement, and evaluation. Thousand Oaks, California: SAGE Publications, Inc.

Meyer, J. H., Knight, D. B., Callaghan, D. P., \& Baldock, T. E. (2015). An empirical exploration of metacognitive assessment activities in a third-year civil engineering hydraulics course. European Journal of Engineering Education, 40(3), 309-327. https://doi.org/10.1080/03043797.2014.960367

Moos, D. C., \& Ringdal, A. (2012). Self-regulated learning in the classroom: a literature review on the teacher's role. Education Research International. https://doi.org/10.1155/2012/423284

Negretti, R. (2017). Calibrating genre: metacognitive judgments and rhetorical effectiveness in academic writing by L2 graduate students. Applied Linguistics, 38(4), 512-539. https://doi.org/10.1093/applin/ amv051

Pintrich, P. R. (2000). The role of goal orientation in self-regulated learning. In Handbook of self-regulation (pp. 451-502): Elsevier.

Serra, M. J., \& Metcalfe, J. (2009). 15 Effective implementation of metacognition. Handbook of metacognition in education, 278.

Tai, J., Ajjawi, R., Boud, D., Dawson, P., \& Panadero, E. (2018). Developing evaluative judgement: enabling students to make decisions about the quality of work. Higher Education, 76(3), 467-481. https:// doi.org/10.1007/s10734-017-0220-3

Van Etten, S., Freebern, G., \& Pressley, M. (1997). College students' beliefs about exam preparation. Contemporary Educational Psychology, 22(2), 192-212. https://doi.org/10.1006/ceps.1997.0933

Vermetten, Y. J., Lodewijks, H. G., \& Vermunt, J. D. (1999). Consistency and variability of learning strategies in different university courses. Higher Education, 37(1), 1-21. https://doi.org/10.1023/A:10035 73727713

Vermunt, J. D. (2005). Relations between student learning patterns and personal and contextual factors and academic performance. Higher Education, 49(3), 205. https://doi.org/10.1007/s10734-004-6664-2 
Wallin, P., \& Adawi, T. (2018). The reflective diary as a method for the formative assessment of selfregulated learning. European Journal of Engineering Education, 43(4), 507-521. https://doi. org/10.1080/03043797.2017.1290585

Wedelin, D., Adawi, T., Jahan, T., \& Andersson, S. (2015). Investigating and developing engineering students' mathematical modelling and problem-solving skills. European Journal of Engineering Education, 40(5), 557-572. https://doi.org/10.1080/03043797.2014.987648

Winne, P. H. (2010). Improving measurements of self-regulated learning. Educational psychologist, 45(4), 267-276. https://doi.org/10.1080/00461520.2010.517150

Winne, P. H., \& Hadwin, A. F. (2008). The weave of motivation and self-regulated learning. Motivation and self-regulated learning: Theory, research, and applications(2), 297-314.

Winne, P. H., \& Jamieson-Noel, D. (2002). Exploring students' calibration of self reports about study tactics and achievement. Contemporary Educational Psychology, 27(4), 551-572. https://doi.org/10.1016/ S0361-476X(02)00006-1

Wissman, K. T., Rawson, K. A., \& Pyc, M. A. (2012). How and when do students use flashcards? Memory, 20(6), 568-579. https://doi.org/10.1080/09658211.2012.687052

Zheng, J., Xing, W., Zhu, G., Chen, G., Zhao, H., \& Xie, C. (2020). Profiling self-regulation behaviors in STEM learning of engineering design. Computers \& Education, 143, 103669. https://doi. org/10.1016/j.compedu.2019.103669

Zimmerman, B. J. (2008). Investigating self-regulation and motivation: historical background, methodological developments, and future prospects. American educational research journal, 45(1), 166-183. https ://doi.org/10.3102/0002831207312909

Publisher's Note Springer Nature remains neutral with regard to jurisdictional claims in published maps and institutional affiliations. 